\title{
Repensando a performance na educação - intuições e problemas na recepção
}

\author{
Rethinking performance in education - insights and \\ reception problems
}

Elaine Conte*

Universidade Federal do Rio Grande do Sul

Resumo A performance configura-se como uma expressão refinada de comunicação, um elemento de troca intersubjetiva para se fazer entender nas esferas artísticas, filosóficas e pedagógicas, facilitando as conversações, criando laços, aproximando os sujeitos na arte de educar. Trata-se de uma retomada da performance pelo caminho da inspiração hermenêutica, que permite sair de certos mecanismos operacionais destituídos de subjetividade para criar possibilidades estético-discursivas. A performance na perspectiva do uso comunicativo agrega todos os produtos da cultura, da arte, da vida cotidiana, da literatura, do cinema, como elementos linguísticos para encontrarmos respostas aos obstáculos do mundo e às necessidades intrínsecas da formação educativa.

PalaVras-Chave: Educação, Performance, Formação.

Abstract Performance appears as a refined expression of communication, an element of intersubjective exchange to be understood in artistic, philosophical and pedagogical spheres in order to facilitate discussions, create bonds, and approximate subjects in the art of educating. It is a retaking of performance through the hermeneutical inspiration, which allows exits from certain operational mechanisms deprived of subjectivity in order to create aestheticdiscursive possibilities. The performance from the perspective of communicative use aggregates all products of culture, arts, daily life, literature and cinema as linguistic elements to find answers to the world's obstacles and the intrinsic needs of educative formation.

KEYWORDS: Education, Performance, Formation. 


\section{Apresentando um enfoque performativo'}

O presente ensaio busca desenvolver novos sentidos para o conceito de performance $^{2}$ na educação, ainda centrado na burocratização e na competitividade, dando voz às discussões críticas e inovadoras que manifestam uma insatisfação desta tendência que impede a criatividade. Hoje, em qualquer ofício, não basta apenas saber executar tarefas utilizando um discurso artificial, mas se exige a competência ${ }^{3}$ linguístico-expressiva de todos, o discernimento, o espírito crítico, o raciocínio lógico, a sociabilidade, os valores éticos, solidários e cooperativos. Pedro Demo (2010, p. 06) diz que "a questão das habilidades vincula-se estreitamente à da politicidade: significa a capacidade humana de alargar suas oportunidades, dentro das circunstâncias dadas, ou de conduzir, até onde possível, seu destino". Assim, compartilhamos a perspectiva de que um projeto educativo centrado na individualidade, consciência, responsabilidade moral e identidade do eu, decorrentes de uma certa compreensão sobre a natureza humana, acaba conferindo à formação reducionismos de comportamentos niveladores (a semelhanças técnicas), em relação à pluralidade das ações humanas.

O debate sobre a performance no Brasil é ainda pouco expressivo no que se refere à preocupação com a formação da competência estética do agir humano na esfera educacional. A investigação das manifestações contemporâneas da performance tem ocorrido por iniciativas ousadas como as de Cohen $(2007)^{4} \mathrm{e}$ de Pereira (2007; 2010), que dialogam com a expressão artística da performance associada às contundentes ações antropológicas como uma arte de fronteira. Guardadas as especificidades das diferentes abordagens, tal performance rompe com convenções que amarram a linguagem, formas e estéticas, sendo visualizada desde as questões da ritualização, da oralidade, da corporeidade, da tecnologia aplicada às performances, até as questões de contexto cultural, num movimento de crítica à verticalidade excludente do agir na multiplicidade do mundo, através da abertura ao olhar estético. Recentemente, estes pesquisadores se propõem a revisitar a precariedade da produção significativa do conceito, sua evolução (consiste na transformação do homogêneo para o heterogêneo da linguagem), que sublinha interpretações históricas e repercussões amplas na pedagogia, na filosofia, na literatura e na arte da expressão. Tais perspectivas, embora distintas, apresentam percepções mais clarificadas de que os processos pedagógicos são fluxos de experiências heterogêneas que organizam interfaces vivenciais com relação aos conteúdos e ao processo de construção do conhecimento intersubjetivo entre os sujeitos. É nesse sentido que a performance desempenha o papel crítico da racionalidade presente entre as linguagens especializadas e o mundo da vida, promovendo o debate das contradições humanas necessário aos processos formativos.

No tocante às questões referentes à performance como unidade ativa da vida (unidade mentecorpocoração), enquanto autoria (também na esteira da autonomia; FREIRE, 1996) e capacidade de ação, Richard Schechner (2000, p. $13)^{5}$ observa que "os experimentos de performance se aproximaram e turvaram as fronteiras entre as artes performativas e entre a arte e a vida". Assim, a performance 
toma um sentido amplo do agir vigoroso, abarcando todos os domínios da área da cultura e da arte, como certos modos de ser, de conduzir, de atuar, de falar e escrever. Schechner associa a performance ao campo sem fronteiras da ação interdisciplinar, intercultural, a uma metáfora da construção coletiva, de uma necessidade humana que temos pela comunicação e interação. Da mesma forma,

é o paradoxo fundamental da performance que cada instância seja diferente das outras, enquanto que teoricamente a ideia mesma de performance baseia-se na repetição e na restauração. Mas nenhuma repetição é exatamente a cópia; os sistemas estão em fluxo constante. (SCHECHNER, 2000, p. 13, tradução nossa)

Com efeito, a performance é um comportamento restaurado (restored behaviour) e vivo sempre ligada à presença, ao corpo, ao cultural, marcando identidades nas circunstâncias transitórias da existência pessoal, social, política, tecnológica. Em outras palavras, a performance abre caminho à intervenção no mundo. "É por isso que o educador progressista, capaz e sério, não apenas deve ensinar muito bem a sua disciplina, mas desafiar o educando a pensar criticamente a realidade social, política e histórica em que é uma presença" (FREIRE, 2000, p. 21-27). Por isso, falamos da força da performance como formação na dinâmica de uma prática educativa radical, estimuladora da curiosidade crítica, à procura das razões de ser dos fatos, como forma de ação especificamente humana, que se funda na interdisciplinaridade.

[...] mais do que um ser no mundo o ser humano se tornou uma presença no mundo, com o mundo e com os outros. Presença que, reconhecendo a outra presença como um "não-eu", se reconhece como "si própria". Presença que se pensa a si mesma, que se sabe presença, que intervém, que transforma, que fala do que faz mas também do que sonha; que constata, que compara, avalia, valora, que decide, que rompe. (FREIRE, 2000, p. 51)

Trata-se aqui de pensar a performance do professor não como ação solitária, mas como uma prática restituída e solidária, que incide necessariamente sobre o real e, ao mesmo tempo, um movimento no qual entramos no jogo da linguagem, numa formação incessante (formatividade) que se constrói no momento da interação com os outros atores. Richard Schechner (2000) afirma que a performance foi desenhada como um guarda-chuva para obras que resistiriam à categorização enquanto fronteiras indistintas. A performance, aos poucos, foi se tornando conceito, agregando sentido de acordo com as pautas de cada época. O autor traz a ideia de que a performance está em todo lugar, enfatizando o ambiente cada vez mais midiatizado em que vivemos, onde nos comunicamos continuamente por uma quantidade ilimitada de meios virtuais. Por tudo isso, o conceito de performance tornou-se, e esta já constitui uma das críticas, um conceito vago e, portanto, disponível para incorporar diferentes tendências, as várias facetas do conceito, entrelaçando um amplo campo de pesquisa e diferentes eventos históricos.

Podemos dizer que, na teoria de Schechner, a teatralidade (conectada à fantasia e à simbolização) corresponde à capacidade que todos os humanos têm de 
atuar perante um público em situações que desarticulam as convenções sociais, inclusive do estético e do teatral. Ao que tudo indica, a natureza da performance "[...] afeta aquilo que é conhecido; a performance, de qualquer jeito, modifica o conhecimento. Ela não é simplesmente um meio de comunicação: comunicando, ela o marca" (ZUMTHOR, 2007, p. 32). A trajetória da performance surge de múltiplas linguagens, formais, transgressoras e conceituais de filósofos e artistas, por isso considera-se como um caminho expressivo no qual as ações humanas têm sido usadas como arma contra conceitos aprisionados na tradição. $\mathrm{O}$ seu uso vai além de um meio de comunicação, produzindo corporeidade, sensação, imaginação, percepção, expectativas, valores, entendimento, enfim, irradiando o vivido e atualizando-o como forma de dinamizar a experimentação do sujeito linguístico. Por tudo isso, sua visibilidade é estética, visto que reintegra o sentido dialético e reflexivo do saber docente que não só indica ou afirma algo, mas comunica e materializa uma multiplicidade de sentidos e relações com os outros sujeitos no mundo. A performance implica a abertura para as questões da atualidade, numa prática permeada de contexto histórico-cultural em que o sujeito assume sua responsabilidade e o seu papel social através da multiplicidade de racionalidades e da qualificação da competência expressiva do agir.

A performance emerge, segundo Paul Zumthor (2007), como uma ocorrência crescente no mundo da cultura que reforça a atividade criativa e do aprendizado sem qualquer preocupação de ordem econômica ou prática, justificada no âmbito do discurso estético-expressivo. Isso porque a performance ${ }^{6}$ vai além de um meio de comunicação científico (transita para uma expressão de caráter estético-reflexivo), produzindo corporeidade, movimento, jogo, sensação, imaginação, percepção, expectativas, valores, entendimento, enfim, irradiando o vivido e atualizando-o como forma de dinamizar a ação do sujeito linguístico. Zumthor vê na comunicação o cerne da ação performativa que pode ser tomada como uma reapresentação de conhecimentos (recriação de saberes e de modos de ver), visto que realiza necessariamente uma transformação intersubjetivamente compartilhada. Este estudioso propõe ainda desnaturalizar olhares que desconsideram a voz (a oralidade em detrimento da escrita), mostrando como é possível pensar o dinamismo da voz na relação existente entre voz e corpo, gesto e poesia, criando uma espécie de experiência virtual, que é ao mesmo tempo movente, viva, comunicativa, expressiva, perceptiva, concreta e sensível. Tal performance intersubjetiva surge na atualidade como uma mudança paradigmática na qual estamos imersos, sendo necessária à interlocução dialógica, pois permite ao corpo comunicar-se num contexto de improvisação próprio da vida, revitalizando a percepção pelos sentidos e a sensibilidade ao agir pedagógico, pois não há educação em que as palavras e os corpos estão reificados.

Desse modo, manifesta-se uma ação expressiva que difere do que é conhecido e repetido, constituindo-se num espaço de abertura às relações humanas e às metamorfoses (cujo poder mimético se manifesta na práxis linguística). Além disso, se a linguagem é uma forma de agir no mundo e se essa prática visa superar a instância representacionista da linguagem na modernidade, é de se supor que, no paradigma da intersubjetividade, deve haver uma possibilidade 
de reformulação da estrutura que dá amparo à performance como uma maneira de dar vida às ideias e romper com convencionalismos. A linguagem é paradoxal, porque tanto pode provocar marcas na personalidade (traumas se proferida com agudeza) e instrumentalizar as relações com os outros quanto pode fundar novos modos de vida e formas de expressão. Fazendo uma analogia com o pensamento de Goffman (1975), podemos dizer que uma das exigências da formação (docente) é que os sujeitos/atores aprendam coletivamente um número suficiente de formas de expressão para serem capazes de dirigir o papel social que the seja dado. Afinal, assim como uma performance, nós podemos ocupar diferentes papéis e fazer uma viagem entre fronteiras de identidade e do conhecimento, questionando a fixidez das estruturas de significação que definem padrões dominantes. Mas, frequentemente, essa dimensão do conhecimento sensível referente à expressão emitida pelo agente/professor é abordada apenas por instruções de como ensinar pedagogia (uso estratégico e instrumental da linguagem) e não de como agir (visão intencional e complexa, que alia as dimensões cognitivo-instrumental, práticomoral e estético-expressivo). Geralmente, espera-se que o educador já saiba bem como usar as construções discursivas da voz, do gesto e do corpo na atividade profissional, o que torna impensável a performance na educação.

Dentro desse contexto, questiona-se: por que a dimensão performativa nos processos de formação de professores ficou restrita apenas ao improviso da apresentação de um trabalho? Do ponto de vista performativo da linguagem, o debate permite afirmar que a guinada linguistica ${ }^{7}$, por ter ocorrido inicialmente no interior do semanticismo, teve como consequência o processo de abstração que acabou recortando a linguagem do seu caráter autorreferencial (que desperta a emoção/sensibilidade). O importante, explica Habermas (1990, p. 55), é ir além da essencialidade das formas de proposição, visto que ela "prescinde da situação da fala, do uso da linguagem e de seus contextos, das pretensões, das tomadas de posição e dos papéis dialogais dos falantes". Daí pode-se inferir que a performance abre possibilidades interpretativas, recriada pela atitude hermenêutica ${ }^{8}$ (que é palavra), porque se insere na mobilidade da linguagem viva, irradiando múltiplas significações para a realização do que se expressa.

\section{A performatividade da linguagem}

Os contornos do que hoje podemos chamar de performance remontam aos antigos gregos cuja tradição concorda que a representação de um texto dramático é uma performance, uma prática compartilhada e relacionada com o mundo. Aristóteles (384-322) abdicou a separação platônica entre imagens dos mundos inteligível e sensível, propondo em seu lugar a teoria do ato e da potência, uma ideia de movimento a algo que pode ser potencializado no próprio ente. Nada poderia existir na inteligência humana sem antes passar pelos sentidos. Já com seu tratado sobre a Poética (1992) observa que o sentido relativo à arte de ensinar e de aprender pertence à esfera da atividade prática ligada à poesia, tendo sua origem na imitação e intuição. Para Aristóteles, a ação performativa (de gênero dramático) é entendida como aquele agir no qual o ator imita as ações humanas e as atualiza 
através da expressão imediata em cada (re)apresentação. Nesse sentido, o estéticoexpressivo era o caminho segundo o qual algumas práticas eram problematizadas como phronèsis. ${ }^{9}$ De acordo com Trevisan (2000), o cerne da teoria aristotélica é a práxis, o agir humano no lugar costumeiro da vida, relacionada com o caráter e direcionada pela racionalidade, pois é da ação excelente (performance) que se chega à virtude.

Aristóteles, no tratado sobre a Retórica (1932), apresenta um conhecimento da arte de persuadir, dizendo que tem por objetivo encontrar um conhecimento persuasivo e confiável acerca das técnicas ${ }^{10}$, bem como dos limites da ação humana em cada situação. A retórica é uma forma de orientação ao trabalho do orador/professor na busca pelo discurso desejado/aceito pelo público e, ao mesmo tempo, uma possibilidade de revisão autocrítica do discurso. Ainda de acordo com o filósofo, a forma mais completa das belas-artes é a tragédia, porque produz a purificação ou catarse de circunstâncias sociais que precisam ser conhecidas. Segundo Zumthor (2007), a proposta de catarse se aproxima da ideia realizativa de comunicar, que não consiste somente em passar uma informação, mas realizar algo (é mais que receber) e sofrer uma transformação concernente ao conjunto da sensorialidade humana. Por tal forma poética de discurso nossos sentidos tornam-se movidos por outra dramaturgia, outra literatura ou outras formas de expressão e racionalidade, mas, para isso, precisamos nos envolver de alguma maneira nos modos de vida e cultura dos grupos humanos que as produzem para apreendermos seu significado. Contudo, a dimensão da arte (performativa) na educação produz um (des)equilíbrio das forças vitais, integrando uma visão ética e estética de criação do saber no mundo.

A raiz do conceito performance deriva do verbo inglês to perform, termo correlato do substantivo ação, que revela, segundo a tese de Austin (1990, p. 25), que num ato de fala performativo realizamos efetivamente uma ação. No entanto, a natureza dinâmica de um ato de fala reapresentado sob a forma da performance nasce de uma relação intersubjetiva, pois só tem sentido quando experimentado com o outro, promovendo reflexividade e criticidade. Por essa razão, Austin (1990) observa que a elocução performativa dita por um ator no palco é vazia, uma vez que ele representa um personagem (objetivado) com regras estipuladas por uma poética. Em contrapartida, o professor é o autor do seu próprio script, pois não pretende representar um outro sujeito distanciado de sua linguagem e gestos, ou habitar um espaço e tempo fictícios, mas apresenta uma atualidade e um forte caráter público de interação com atores sociais (múltiplas vozes). Mas a performatividade, ao se contrapor à representação, não estaria se diferenciando também da teatralidade? $\mathrm{Na}$ verdade, a performance provoca uma crise de representação do inteligível e muda o aspecto sob o qual este fenômeno é visto, porque não se justifica mais na descrição e adequação objetiva entre palavras e a realidade, mas demanda a presença, o imaginário e a subjetividade do agente/professor que questiona e cria expressões. Além disso, de Kant a Adorno, a dimensão estética (nível pré-discursivo) exerceu a função de reconciliação entre sujeito e objeto, resistindo ao enquadramento no plano da representação e antecipando a reconciliação dos distanciamentos do conhecimento como contrapartida da dominação técnica efetuada pelo homem 
sobre a natureza. Atualmente, pode-se chamar de performance uma infinidade de manifestações expressivas, artísticas e técnicas, aparecendo na modernidade tanto como "representação de um papel" (na perspectiva de Goffman), quanto como forma de comunicação verbal eficiente (na abordagem de Austin), entre outras. Trata-se de uma perspectiva de performance que não é consensual, porque isso significaria reduzir a noção movente e aberta de performance, proveniente de inúmeras discussões nos diferentes campos do saber, a um conceito discursivo que limita a palavra como linguagem artística.

Como observa Demo (2010), à medida que percorremos diferentes teorias, percebemos que há uma colonização sistêmica do discurso sobre a performance na educação que gira em torno das mudanças econômicas ocorridas no mundo do trabalho (frenético, como obrigação ou dever), tais como a intensificação do uso, a fragmentação do conhecimento e das relações humanas, a supervalorização da informação e da técnica. Nessa perspectiva, a performance é tratada como uma cultura de gestão do desempenho e avaliação (e posterior retorno do investimento), tendo uma forte tendência de calcular desempenhos para, genericamente, melhorar a qualidade da educação. A necessidade de investimento na formação docente aparece com destaque (como expressão da proletarização do trabalho ${ }^{11}$ e desvalorização profissional), mas sustentada exclusivamente por um discurso que busca enfatizar o caráter inovador das tecnologias na formação como forma de satisfazer o desejo de realizar um bom trabalho obedecendo à lei do menor esforço. Nesse contexto, surgem programas de formação e treinamento de pessoal para que a educação cumpra seu papel social, sendo que, muitas vezes, tais cursos se convertem em centros de titulação e especialização, reflexo da divisão social do trabalho e da consequente depreciação do agir docente ${ }^{12}$. Com tais práticas instituídas, baseadas no saber-fazer, ocorre a subsunção da racionalidade comunicativa à razão instrumental. Flickinger (2009, p. 67) tece uma análise da transformação social em andamento, constatando que "a sociedade do trabalho se efetua por meio da economização abrangente do homem", sendo valorizado pelo que ele produz e regido pelas diretrizes econômicas. As instituições educativas também são afetadas por este padrão de qualificação do mercado de trabalho, que tudo mede e quantifica através das diversas avaliações verificativas e burocráticas, reduzindo os espaços formativos a regulamentos (inúteis) quanto à sua eficiência e danosos à sua criatividade.

Podemos deduzir também que o conceito de performance tem suas raízes filosóficas no pragmatismo ${ }^{13}$ que sustenta a ideia de que, para trabalhar bem, as pessoas precisam abandonar a atitude racionalista, dogmática, no sentido de ir contra o artificial e as pretensas verdades, que surgem no cotidiano. Por trás dessa convicção está o conceito de experiência (Erlebnis e Erfahrung) ${ }^{14}$ que pode influenciar nosso agir com os outros dentro do processo vital.

As ações humanas praticadas nas relações intersubjetivas intensificam e mobilizam o convívio com as diferenças como um modo do sujeito conhecer a si mesmo, especialmente quando falamos do ofício docente. O primeiro movimento seria uma problematização crítica do papel a ser desempenhado pelo professor, que 
engloba as relações plurais e construtivas da formação alicerçadas na racionalidade comunicativa, para não sucumbir ao vício do instrumentalismo dominante do pensamento e da ação determinados pelo vínculo fins-meios.

Inspirado pela fenomenologia e pelo pragmatismo, Paulo Freire (1984) afirma que a performance se dá através da entonação da palavra, do gesto, do corpo, e isso revela uma maneira de tornar concretos os saberes discutidos. Nas palavras de Freire (1983, p. 70), "a comunicação eficiente exige que os interlocutores incidam sua 'admiração' sobre o mesmo objeto; que o expressem através de signos linguísticos pertencentes ao universo comum a ambos [...]". $\mathrm{Na}$ medida em que recria culturalmente as possibilidades para a construção do conhecimento, o professor, por meio de sua expressividade linguística, desenvolve uma postura dialógica, aberta, curiosa, indagadora enquanto fala ou ouve, despertando entre os educandos a curiosidade pela percepção da realidade. A inserção da dimensão da corporeidade na prática pedagógica está ligada ao encontro com o outro sujeito, ao momento presente em que os corpos se reúnem no espaço educativo para o estabelecimento de troca de conhecimentos, de experiências e práticas, impulsionando a recriação de saberes. Nesta teoria freireana da ação, exatamente porque é revolucionária, é possível falar de atores em relação intersubjetiva e interativamente continuada. Mas o professor parece querer esconder o próprio corpo por trás da profissão, como um corpo inconsciente no fazer sem pensar, sem sentir, sem dialogar. Para Freire (1995, p. 92),

A importância do corpo é indiscutível; o corpo move-se, age, rememoriza a luta de sua libertação, o corpo afinal deseja, aponta, anuncia, protesta, se curva, se ergue, desenha e refaz o mundo. [...] Há muito sensualismo que o corpo guarda e explicita, ligado até mesmo à capacidade cognoscente. Acho um absurdo afastar $o$ ato rigoroso de saber o mundo da capacidade apaixonada de saber. Eu me apaixono não só pelo mundo, mas pelo próprio processo curioso de conhecer o mundo.

Evidentemente, o corpo é um campo de expressão da consciência (com sensações que enriquecem o ato racional), reconhecido intersubjetivamente, que dá sentido às ações humanas quando se manifesta de maneira viva, podendo alcançar o significado do gesto, do olhar, do silêncio ${ }^{15}$ e outras expressões corporais. O trabalho educativo precisa ser mobilizado de corpo inteiro, como um processo permanente e prazeroso que desperta a curiosidade, o toque humano, as práticas lúdicas e a diversidade de linguagens. Nas palavras de Freire (1996, p. 63-64), "estar no mundo sem fazer história, sem por ela ser feito, sem fazer cultura, sem 'tratar' sua própria presença no mundo, sem sonhar, sem cantar, sem musicar, sem pintar [...], sem aprender, sem ensinar, sem ideias de formação, sem politizar, não é possível", pois é no inacabamento do ser que a educação se alicerça. A educação não pode ignorar a corporeidade do professor e do educando, os ritmos e movimentos corporais podem liberar tensões, desinibir e alegrar os sentimentos necessários para o desempenho pedagógico. Para estimular o desenvolvimento da linguagem o professor precisa estar disponível corporalmente para que, junto com a turma, se proponha a descobrir e aprender nas fantasias, imaginação e na alegria, 
indo além do mero conhecimento, mas reeducando e integrando saberes pela ação do corpo lúdico no processo formativo, da arte, da música, das coreografias e ações compartilhadas. Afinal de contas, se não formos sensíveis a nós mesmos, como poderemos ser sensíveis aos outros?

\section{Como romper com a verticalidade da performance?}

Diante do predomínio do cientificismo explicativo (monológico e verbalista), podemos perceber que é na experiência estética que a performance adquire sua visibilidade, pois a estética agrega a comunicação e traz elementos para desreprimir o sujeito das cópias engessadas do recalque. Discorremos que há uma decadência estético-expressiva pela compreensão abstrata, inexpressiva e cristalizada dos discursos instituídos, como observa Habermas (1996, p. 285): "A linguagem natural de que se faz uso na educação parece que somente se desenvolve de forma auxiliar com fins didáticos, tomando instrumentalmente a linguagem a seu serviço". Essa tendência à pedagogização existe desde o século XVIII, o que transforma a educação em um sistema técnico e administrativo (abstracionismo pedagógico), regulamentado por um sistema legaliforme de efeito paralisante nas próprias práticas educativas (fixa até a palavra efêmera que tem sua verdade na transitoriedade e vê a mudança como algo externo às próprias práticas). Vemos em Habermas a expressão da performance como uma linguagem surgida das rupturas do projeto moderno, capaz de desenvolver uma sensibilidade para o uso comunicativo da fala a qual agrega as formas de racionalidade (técnico-instrumental, práticomoral e estético-expressiva) necessárias à globalidade da formação humana. A performance intersubjetiva é condição sine qua non para a comunicação efetiva, tendo em vista que hoje dificilmente existe atividade humana que não seja uma performance para alguém, um processo em que o cognitivo e o estético (formas de expressão/linguagens artísticas) estão entrelaçados.

A ampliação conceitual como dimensão presente no gesto estético da prática docente é apresentada por um cuidadoso estudo de Pereira (2009; 2010), que revela o problema da comunicação docente como déficit da função poética e sensível da linguagem integrada à percepção do corpo na modernidade. Pereira (2010) vê no gesto um sistema expressivo plástico e ativo, carregado de significação, intensidade e amplitude, porque fala tanto ou mais que a palavra e permite redimensionar o sentido das ações, das condutas humanas diante do outro. Em suas palavras,

[...] a dimensão performativa do gesto, pelo ato estético e pela experiência estética - permite postular uma educação de ato - como atualização de potência, para recobrarmos o sentido cunhado por Aristóteles do termo -, uma educação atualizadora não orientada por princípios meramente utilitários, técnico-instrumentais signos de uma educação moderna, reducionista, estabilizadora e reprodutora de sentidos (sensações, significados, finalidades) [...], que não se reduz a um exercício infértil e retentivo de descriçãoprescrição do real, de emudecimento do real. (PEREIRA, 2010, p. 557; grifos do autor) 
No que se refere à ação educativa como ato estético e expressivo, vale salientar que ela passa pelo movimento performativo do corpo enquanto prática formativa, quase artística, confluindo ética e estética no compartilhamento e ampliação dos sentidos expressos pelo uso que se faz da palavra. Podemos considerar que a performance é uma arte de intervenção, que visa uma transformação nos sujeitos, assim como a arte de educar, sendo permeada pelo processo, pelo risco inerente à performance, pela alternância dos criadores/atuantes e pelas vicissitudes do percurso. Tudo indica que "só podemos apreender alguma coisa com a resistência, performativamente vivenciada da realidade, na medida em que tematizamos as conviçcões implicitamente postas em questão e aprendemos com as objeções de outros interlocutores" (HABERMAS, 2004, p. 24). A performance promove ainda o debate coletivo das contradições humanas como processo de devir, como um conhecimento de revisão dialógica, importante para levar a cabo o jogo performativo da formação como autocriação da própria experiência, como inquietação de si na relação com os outros e com a linguagem. Cabe lembrar que a educação é, necessariamente, negociação dos significados compartilhados pela cultura em seus diversos exemplos de realização discursiva.

O que se vislumbra é, entre outras coisas, o momento de repensar a educação, partindo da emergência da performance que agrega todos os produtos da cultura, da arte, da vida cotidiana, da literatura, do cinema, como elementos que valorizam o estético-expressivo nas práticas formativas e pedagógicas de validade criticáveis. Além disso, surge como uma possibilidade de superar os limites da linguagem e buscar transcendê-los pelo envolvimento ativo numa prática sempre aberta à iniciativa de aprender pela palavra enquanto elemento sensível. É performando papéis que nos constituímos num perpétuo e necessário desequilíbrio, pois estamos sempre atuando e exercitando uma autocrítica mesmo que ela não seja evidente (GOFFMAN, 1975).

A performance é sempre uma experiência presente e compartilhada, uma multiplicidade de vozes contrastantes na experiência, um jogo de relação com a alteridade que nos modifica e nos intensifica como seres humanos, constituindo num convite à ação e à abertura ao reaprender, única forma de legitimar a arte de ensinar. Sendo assim, com a performance "se introduz uma atitude realizativa (performative Einstellung) de tipo global, para dar conta de que com cada ato de fala os participantes da comunicação se referem simultaneamente a algo no mundo objetivo, no mundo social e no mundo subjetivo" (HABERMAS, 1987, p. 422; grifos do autor). Nessa versão, a forma de atuação dos professores no mundo revela que os processos de aprendizagem performativos e realizativos precisam contemplar os atos de fala descritivos, expressivos e regulativos, que encontram apoio na ação dramatúrgica (é simultaneamente estética, artística e expressiva, preconizada por Erving Goffman) ${ }^{16}$. A ação dramatúrgica como parte constitutiva dos enunciados enraizados em práticas formativas do professor/ator pode servir à autoexpressão e ampliar as dimensões constitutivas da racionalidade prático-estética, fluidificando as relações de poder estabelecidas e criando assim novos espaços ao agir comunicativo por meio de interações em situações concretas. Analisar como se dá a performance no processo formativo é ajudar os professores a descobrir como 
interagir, tornando sua ação mais sedutora, afetiva, digna e realizadora. A dimensão performativa na educação nos possibilita seguir pensando o sentido do texto, do corpo e da própria racionalidade da ação educativa como expressão intersubjetiva realizada efetivamente na polissemia das palavras e visões de mundo que visam sensibilizar o outro para a recriação.

\section{Referências}

ARISTÓTELES. Poética. Trad. Eudoro de Souza. São Paulo: ARS Poética, 1992. ARISTÓTELES. Rhétorique. Paris: Belles Lettres, 1932.

AUSTIN, J. L. Quando dizer é fazer. Porto Alegre: Artes Médicas, 1990.

BENJAMIN, W. Charles Baudelaire: um lírico no auge do capitalismo. Obras Escolhidas III. São Paulo: Brasiliense, 1989.

COHEN, R. Performance como linguagem. 2. ed. São Paulo: Perspectiva, 2007.

DEMO, P. Habilidades e competências: no século XXI. Porto Alegre: Mediação, 2010.

DEWEY, J. A arte como experiência. In: DEWEY, J. Trad. Murilo Otavio Rodrigues Paes Leme. São Paulo: Abril Cultural, 1980. p. 87-105. (Coleçăo Os Pensadores)

FLICKINGER, H. G. A dinâmica do conceito de formação (Bildung) na atualidade. In: CENCI, A. C.; DALBOSCO, C. A; MÜHL, E. H. (Org.). Sobre filosofia e educaçáo: racionalidade, diversidade e formação pedagógica. Passo F undo: Ed. Universidade de Passo Fundo, 2009.

FREIRE, P. Extensáo ou comunicaçáo. Rio de Janeiro: Paz e Terra, 1983.

FREIRE, P.; GUIMARÃES, S. Sobre educaçáo: diálogos. v. II. Rio de Janeiro: Paz e Terra, 1984.

FREIRE, P. A Educaçáo na cidade. 2. ed. São Paulo: Cortez, 1995. Terra, 1996.

Pedagogia da autonomia: saberes necessários à prática educativa. São Paulo: Paz e

FREIRE, P. Pedagogia da indignaçáo: cartas pedagógicas e outros escritos. São Paulo: UNESP, 2000.

GADAMER, H. G. Verdade e método. 4. ed. Trad. Flávio P. Meurer. Petrópolis: Vozes, 2002.

GOFFMAN, E. A representaçáo do eu na vida cotidiana. Petrópolis: Vozes, 1975.

HABERMAS, J. Verdade e justificaçáo: ensaios filosóficos. São Paulo: Loyola, 2004.

. La Lógica de las ciências sociales. 3. ed. Madrid: Tecnos, 1996.

. Pensamento Pós-Metafísico: estudos filosóficos. Trad. Flávio Beno Siebeneichler. Rio de Janeiro: Tempo Brasileiro, 1990.

HABERMAS, J. Teoría de la Acción Comunicativa I: Racionalidad de la Acción y Racionalización Social. Madrid: Taurus, 1987.

PEREIRA, M. A. A dimensão performativa do gesto na prática docente. Revista Brasileira de Educaçấo. v. 15, n. 45, set./dez. 2010, p. 555-597.

PEREIRA, M. A. Usos da palavra. Tese de Doutorado. Universidade Federal do Rio Grande do Sul. Programa de Pós-Graduação em Educação. Porto Alegre - RS, 2007. 
PEREIRA, M. A.; ICLE, G. Materialidade da comunicação docente: conhecimento, uso de palavra e experiência estética. In: ANPED, 32ª Reunião, GT 24, 2009.

SENNETT, R. O artífice. Trad. de Clóvis Marques. 2. ed. Rio de Janeiro: Record, 2009.

SCHECHNER, R. Performance: teoría y prácticas interculturales. Buenos Aires: Libros Del Rojas, 2000.

TREVISAN, A. L. Filosofia da educaçáo: mímesis e razão comunicativa. Ijuí, Ed. da UNIJUÍ, 2000.

ZUMTHOR, P. Performance, recepçáo e leitura. Trad. Jerusa Pires Ferreira e Sueli Fenerich. São Paulo: Cosac Naify, 2007.

\section{Notas}

${ }^{1}$ Versão ampliada do trabalho apresentado no VII Congresso Internacional de Educação - Profissão Docente: há futuro para esse ofício? (Unisinos, 22 a 24 de agosto de 2011).

${ }^{2}$ Ao termo performance são atribuídos significados tais como ação, expressão, desempenho, resultado, atuação, execução, competência, habilidade, modo de comportamento, (re)apresentação e reelaboração de conhecimentos, etc.

${ }^{3}$ Competência é entendida no sentido de aprender a agir comunicativamente, que realça as habilidades de iniciativa humana do contexto social, as capacidades expressivas de aprender e conhecer os próprios limites para superá-los.

${ }^{4}$ Para Cohen (2007, p. 27-45), o que caracteriza a passagem do happening (acontecimento, evento cujas manifestações incluem várias mídias, como artes plásticas, teatro, música, dança, etc.) para a performance (anos 70) é o aumento de preparação e de esteticidade, em detrimento do improviso e da espontaneidade. Cabe destacar que a performance art é a expressão utilizada pelos americanos para caracterizar uma arte afetada pela emoção humana segundo os três axiomas da cena: atuantetexto-público, sem os quais a performance não se realiza. A performance atua dialeticamente como uma arte de intervenção, modificadora, tanto a nível do princípio do prazer - com um fluxo criativo e um processo de atuação dionisíaco quanto a nível do princípio de realidade - com uma clara preocupação de organização da mensagem elaborada.

${ }^{5}$ Entre 1966 e 1973, Schechner, influenciado pelo campo do teatro e da antropologia, estabeleceu uma área de estudos que chamava as atividades de performance do homem, incluindo neste âmbito as representações, jogos, esportes, teatro e ritual. Nesse período, o autor considerava a performance um tipo de conduta comunicativa que formava parte de rituais formais, reuniões públicas e outros meios culturais de trocar informações, conhecimentos, mercadorias e costumes, atribuindo um reconhecimento da performance em termos (inter)culturais e globais.

${ }^{6} \mathrm{~A}$ distinção inicial entre procedimentos constatativos (dizer) e performativos (falar) é analisada e ultrapassada pelo próprio Austin quando considera que tais atos são inseparáveis, e afirma a teoria da pluridimensionalidade dos atos de fala (não abstrações, mas a totalidade do ato de fala em todos os seus momentos). Foi assim que articulou os diferentes momentos constitutivos da linguagem enquanto tipo de ação humana. Para Austin (1990), todo dizer é um fazer, mesmo o ato de fala mais simples é uma realidade complexa, contém muitas dimensões. É essencialmente uma ação social, pois linguagem e sociabilidade se conjugam mutuamente no horizonte a partir do qual os indivíduos exprimem a realidade. Falar é transmitir informações, mas é também uma forma de agir sobre o interlocutor e sobre 
o mundo circundante. A performance coloca em ação habilidades de entendimento como as contradições humanas, a razão e a sensibilidade, bem como a complexidade de se expressar (única em seu vir a ser) na semântica de contornos abertos e imprecisos de interpretação.

${ }^{7}$ A expressão virada linguística (linguistic turn) refere-se às movimentações no campo do discurso e da linguagem que passam a ser considerados constituidores da realidade. Wittgenstein (1889-1951) dedicou especial atenção às questões da linguagem para conceder sentido ao falar como condição de possibilidade ao uso apropriado das palavras, do que depende de necessidades, dos jogos de linguagem, do meio, de desejos, das capacidades sensórias, que não são redutíveis a razões explicativas.

${ }^{8}$ Gadamer (2002) é o primeiro a acentuar a abertura ao diálogo como algo vivo, no sentido de afirmar que é uma ilusão pensar que seja possível ter a última palavra. Fazendo uma analogia com a educação, também não é possível uma Pedagogia segura de seus fundamentos, da ação a ser realizada, do gesto ou olhar a ser feito, das palavras a serem ditas. Não haveria orador nem arte da fala se as relações humanas não fossem sustentadas pela compreensão de um diálogo perturbado e pelo acordo (que devesse ser procurado), enraizado no devir das realidades inapreensíveis, na ação e na sensibilidade para o acontecimento que se apresenta.

${ }^{9}$ Para Aristóteles, a phronèsis (a prudência ou a sabedoria prática) capacita o ser humano eticamente a agir bem, pela justa medida (meio-termo) de arriscar-se à ação criadora e, no mesmo ato, dominá-la. Aristóteles defende ainda que o discurso decorre da estrutura intuitiva de uma emissão. Em meados do século XVIII, a palavra virtuose passa a enfatizar um profissional de grande curiosidade que alimenta a curiosidade pela força da simpatia, com informações bem tiradas e as usa na conversa elegante (SENNETT, 2009).

${ }^{10}$ Qualquer técnica de discurso é um ajuste permanente entre o idealizado e o que se faz ou pode ser feito, porque uma técnica não pode ser precisa, rigorosa, por ser condicionada, contingente e imprevisível. Então tanto a phronèsis quanto a thecné são realidades que são produzidas pela ação humana e podem mudar.

${ }^{11}$ Embora a sociedade brasileira associe o nível de escolaridade a melhores oportunidades de trabalho, e que a exigência moderna demande profissionais versáteis, polivantes e autônomos, o que prevalece é uma tendência a simplificar e desqualificar os processos de trabalho, utilizando a paixão por ensinar do professor para precarizar o salário da profissão. A grande maioria dos professores no mercado de trabalho atua com uma formação mínima por falta de condições financeiras para subsidiar a continuidade dos estudos no ensino superior.

${ }^{12}$ Tal aposta conduz a especialização burocrático-funcional da produção (repetir um só gesto desmotivado, acrítico e sem resistência) e a racionalização (expulsa aquilo que não é racional, a saber, os valores movidos pela emotividade, estética e, em parte também a ética), exatamente como fará Chaplin, ironicamente, em Tempos Modernos (1936).

${ }^{13}$ Em linhas gerais, o pragmatismo defende que um projeto só tem valor se tiver efeito prático, se for útil (a utilidade é que dá sentido e valor às coisas). A experiência está subordinada a efeitos práticos da mesma, devendo produzir soluções voltadas para os fatos concretos, para a ação e o poder. Entre seus adeptos temos Richard Roty, Richard Bernstein e Richard Sennett, cujo impulso básico está no envolvimento com as atividades humanas comuns, plurais e construtivas. Em nossa percepção, a educação e especificamente os modelos de formação de professores foram fortemente atingidos pela perspectiva pragmatista de valorização dos aspectos técnicos-instrumentais da formação (saber-como), tendo John Dewey como um grande difusor pela via da linguagem. John Dewey reconhece que os 
processos de ensino e de aprendizagem não podem ser regidos por fórmulas tecnicistas ou por relações de tradição e autoridade, defendendo o ensino pela ação e não pela instrução, pois o objetivo da educação não é só o conhecimento, mas o crescimento. Cabe destacar ainda que, para Dewey (1980, p. 98), "a arte denota um processo de fazer e obrar. Isto é tão verdadeiro das belas-artes quanto da arte tecnológica”, pois o trabalho que permanece permeado pela atitude lúdica é arte.

${ }^{14}$ Erlebnis designa uma sensação que causa alguma coisa, um acontecimento ou relação com uma impressão emocional íntima; Erfahrung designa um fato, ação ou relação que nos volta para fora e antes requer habilidade (para os objetos em si e práticas impessoais) que sensibilidade. Na modernidade a ênfase recai mais na Erfahrung que na Erlebnis. A partir dos estímulos do tempo presente, somos consumidos pelo registro das vivências (Erlebnis) numa espécie de embotamento da experiência, imagem cara a Walter Benjamin (1989), em que todas as nossas energias são despendidas para aparar os choques na multidão. Acontece que somos solicitados a todo instante a fazer escolhas, sem tempo para compreendermos ou para produzirmos um saber sobre nós mesmos.

${ }^{15} \mathrm{O}$ silêncio faz parte do próprio uso criativo da linguagem e pode liberar o sentido da crítica e resistência, pois as vozes do silêncio dão margem às diferenças comunicativas e a emergência de sentidos sempre inconclusos e tensos.

${ }^{16}$ A interação face a face é definida por Goffman (1975, p. 23) “como a influência recíproca dos indivíduos sobre as ações uns dos outros, quando em presença física imediata. O termo encontro também seria apropriado. Um desempenho pode ser definido como toda atividade de um determinado participante, em dada ocasião, que sirva para influenciar, de algum modo, qualquer um dos outros participantes". De acordo com o autor, o mundo é um teatro e cada um de nós é ator, que realiza uma atividade e dá um espetáculo para benefício de outros.

* Elaine Conte - Professora Doutora em Educação pela Universidade Federal do Rio Grande do Sul, Porto Alegre, Rio Grande do Sul, Brasil.

\section{Correspondência}

Elaine Conte - Universidade Federal do Rio Grande do Sul, Faculdade de Educação.

Av. Paulo Gama, s/n

CEP: 90046-900 - Porto Alegre, Rio Grande do Sul, Brasil.

E-mail: elaineconte.poa@gmail.com

Recebido em 18 de março de 2012

Aprovado em 10 de fevereiro de 2013 